\title{
Tersine Lojistik Alanındaki Yayınların Bibliyometrik Analiz Yöntemiyle Değerlendirilmesi
}

\author{
Gamze ALKAN ${ }^{1}$ \\ Burcu YILMAZ ${ }^{2}$ \\ Suzan OĞUZ
}

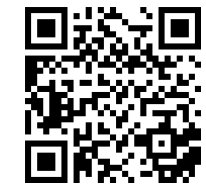

\begin{tabular}{ccc}
\hline $\begin{array}{c}\text { Geliş Tarihi/ Received } \\
03 / 03 / 2020\end{array}$ & Kabul Tarihi/ Accepted & Yayın Tarihi/ Published \\
$15 / 05 / 2020$ & $15 / 07 / 2020$ \\
\hline Citation/Atıf: Alkan, G. ve Yllmaz, B. ve Oğuz, S., (2020), Tersine Lojistik Alanındaki \\
Yayınların Bibliyometrik Analiz Yöntemiyle Değerlendirilmesi, Atatürk Üniversitesi Íktisadi ve \\
İdari Bilimler Dergisi, 34(3): $711-729$, DOI: $10.16951 /$ atauniibd.698202 \\
\hline
\end{tabular}

Öz: Günümüzde firmalar, giderek artan rekabet ortamında varlığını sürdürebilmek için maliyetlerini en düşük seviyeye indirmek, yasalara uyum sağlamak, çevre dostu üretim ve tüketimi sağlamak, sosyal sorumluluklarını yerine getirmek gibi amaçlarla tedarik zinciri yönetiminin en önemli parçalarından biri olan tersine lojistiğe daha fazla önem vermektedirler. Bu sebeple son yıllarda tersine lojistik konusuna olan ilgi de artmaktadır. Bu çalışmanın amacı, 20002019 yılları arasında Web of Science (WOS) veri tabanından alınan tersine lojistik ile ilgili 1850 makalenin bibliyometrik analiz yöntemi ile incelenmesi ve bu alanda yapılan çalışmaların seyrinin yıllar içerisinde nasıl değiştiğinin belirlenmesidir. Yapılan analizler sonucunda tersine lojistik alanında yapılan yayınlarda en yüksek atıf sayısının 2000 yılında gerçekleştiği, en sık kullanılan anahtar kelimenin yönetim (management) olduğu, tersine lojistik kavramının 2007 yılından sonra daha sık kullanıldığı, bu alanda en fazla makale yayınlayan derginin Journal of Cleaner Production olduğu, en fazla yayın yapan üniversitenin Tahran Üniversitesi olduğu, Kannan Govindan'ın bu alanda en fazla yayın yapan araştırmacı olduğu ve bu alanda en fazla çalıșma yapan ülkenin $\mathrm{ABD}$, en fazla işbirliği yapan ülkelerin ise $\mathrm{ABD}$-Çin olduğu sonucuna ulaşılmıştır.

Anahtar Kelimeler: Tersine Lojistik, Lojistik, Bibliyometrik Analiz

A Bibliometric Analysis of Publications Related to Reverse Logistics

Abstract: Today, companies pay more attention to reverse logistics, which is one of the most important parts of the supply chain management, for purposes such as to be able to survive in the increasingly competitive environment in global markets, to minimize costs, to comply with the laws, to provide environmentally-kind production and consumption, and to fulfill their social responsibilities. Therefore, the interest in reverse logistics has also increased in recent years. The aim of this study is to analyze 1850 publications related to reverse logistics, which were retrieved from the Web of Science (WOS) database between 2000-2019 years by bibliometric analysis

${ }^{1}$ Doktora Öğrencisi Akdeniz Üniversitesi, Sosyal Bilimler Enstitüsü, Uluslararası Ticaret ve Lojistik Bölümü, https://orcid.org/0000-0001-9624-084X

${ }^{2}$ Doktora Öğrencisi Akdeniz Üniversitesi, Sosyal Bilimler Enstitüsü, Uluslararası Ticaret ve Lojistik Bölümü, https://orcid.org/0000-0002-6004-0640

${ }^{3}$ Arş. Gör. Çăg Universitesi, İktisadi ve İdari Bilimler Fakültesi, Uluslararası Ticaret ve Lojistik Bölümü, https://orcid.org/0000-0003-4876-3173 


\section{Tersine Lojistik Alanındaki Yayınların Bibliyometrik Analiz Yöntemiyle Değerlendirilmesi}

method, and to determine how the evolution of the studies in this field has changed over the years. As a result of the analysis it was concluded that the highest number of citations is in the year 2000, the most frequently used keyword is management, the concept of reverse logistics is used more frequently after the year 2007, the Journal of Cleaner Production is the leading journal in this field, the most productive institution is Tehran University, the most productive researcher is Kannan Govindan, the country with the highest cooperation is the USA, and the countries with the highest number of cooperation are the USA and China.

Keywords: Reverse Logistics, Logistics, Bibliometric Analysis

\section{Background}

\section{EXTENDED SUMMARY}

Increased environmental awareness of customers has led industries to think about environmental operations through Reverse Logistics activities. In this process, reverse logistics has become one of the most important parts of supply chain management. For this reason, businesses have started to care more about Reverse Logistics activities in recent years. Reverse Logistics refers to the activities in the collection phase to reuse, repair, reproduce, recycle or dispose the used product from the customer.

\section{Purpose}

The purpose of this study is to conduct an extensive bibliometric analysis of published academic articles on Reverse Logistics for the period of 20002019. This study is expected to be beneficial in terms of showing the direction and trends of the studies carried out on the subject, and as a guide for the researchers who are interested in doing research in this field.

\section{Method}

In this study, a bibliometric analysis of the 1850 articles found by scanning with the title "Reverse Logistics" from 2000-2019 over the WOS database was made using the $\mathrm{R}$ program. Bibliometric analysis is the use of statistical methods to analyse articles, books and other publications. Accordingly, the developments and trends in the field of Reverse Logistics for the period covered in the analysis were interpreted by visualizing.

\section{Findings}

1850 articles examined within the scope of the analysis were published in 440 different journals. The average number of citations per publication is 28.04. The number of authors per article is three. In the last 20 years, it was found that the year in which the most interest in Reverse Logistics was the year 2000, and when the last years are examined, the number of citations decreased. In articles, the word "management" is the most frequently used keyword after the Reverse Logistics word. Apart from these words, it has been determined that the most frequently used keywords are "model, design, product recovery, performance and optimization" respectively. The word "Reverse Logistics" has been used more frequently in this field, especially since 2007, and has become very popular in 2018-2019. Countries with the highest number of studies related to Reverse Logistics; USA, Canada, Iran, Netherlands and China respectively. 
Turkey ranks 10th in the total number of citations related to this field. In contrast, the countries that cooperate the most in the field of logistics are China and the USA, while the countries that have contributed the most to this area are China, the USA, the UK and India. Tehran University in Iran is the most productive university in the field of Reverse Logistics.

\section{Giriş}

Son yıllarda artan çevresel kaygılar, kurumsal sosyal sorumluluk, sürdürülebilir rekabet gücü gibi nedenlerden dolayı tersine lojistik uygulamaları tüm işletmeler için önem teşkil etmektedir. Tersine lojistik, kullanılmış ürünü yeniden kullanmak, onarmak, yeniden üretmek, geri dönüştürmek ya da elden çıkarmak amacıyla müşteriden toplanması aşamasındaki faaliyetleri ifade etmektedir (Agrawal vd., 2015: 76). Tersine lojistik, tedarik zinciri yönetiminin önemli parçalarından bir tanesidir. Bu alanda yapılan faaliyetler hem gelişmiş hem de gelişmekte olan endüstriler için bir ihtiyaç olarak kabul edilmekte ve bu alana olan ilgi giderek artmaktadır. Müşterilerin artan çevre bilinci, endüstrilerin tersine lojistik faaliyetleri aracıllğıyla çevre operasyonları hakkında düşünmelerine yol açmıştır. Bu süreçte, itici güçler ve engeller gibi etkili faktörlerin incelenmesi ve paydaşların tersine lojistik faaliyetleri konusundaki farklı bakış açılarının değerlendirilmesi de önemlidir (Govindan ve Bouzon, 2018: 318).

Dünyada nüfusun artışına bağlı olarak mal ve hizmetlere olan talep de artış göstermektedir. Bu talep doğrultusunda tüketim miktarı sürekli artmakta ve dünyadaki atık miktarı da giderek çoğalmaktadır. $\mathrm{Bu}$ nedenle çevrenin korunması konusu pek çok ülkenin gündeminde daha yoğun biçimde ele alınmaktadır (Kaçtıŏlu ve Şengül, 2010: 90). Tersine lojistik, çevresel bozulmanın yavaşlamasına veya önlenmesine yardımcı olabilecek organizasyon stratejilerinden bir tanesidir (Sarkis vd., 2010: 338). Sürdürülebilir çevre kavramı, yasal düzenlemeler, firmaların sosyal ve ekolojik sorumluluğu, müşteri talepleri ve ekonomik nedenler gibi faktörler firmalara tersine lojistik faaliyetleri ile ürettikleri ürünleri geri alma ve değerlerini geri kazanma gibi sorumluluklar yüklemektedir (Nakıboğlu, 2007: 182). Temur vd. (2015) bu yasal düzenlemelerin genel olarak ürünlerin yaşam döngülerinin sonunda toplanması, yeniden kullanımı, atık yönetimi ve bununla ilgili sorumlulukların üreticilere yüklenmesi, atık miktarının azaltılması, ürün veya malzeme geri dönüşüm oranlarının artırılması yönünde yaptırımlara sahip olduğunu vurgulamıştır.

Dünya genelinde küreselleşmenin de etkisiyle artan nüfus ile birlikte doğal kaynakların tükenmesi ve çevre kirliliğinin artış göstermesi konusunda endişeler çoğalmaktadır. $\mathrm{Bu}$ sebeple çevre dostu üretim ve tüketimin gerçekleştirilebilmesi için firmaların üzerindeki toplumsal ve yasal baskılar artmaktadır. $\mathrm{Bu}$ nedenle işletmeler son yıllarda tersine lojistik faaliyetlerini daha fazla önemsemeye başlamışlardır. Bu durum ile birlikte akademik alanda 
Tersine Lojistik Alanındaki Yayınların Bibliyometrik Analiz Yöntemiyle
Değerlendirilmesi

tersine lojistik alanında yapılan çalışmaların sayısında artış olduğu görülmektedir.

$\mathrm{Bu}$ çalışmanın amacı, tersine lojistik alanında yayınlanan makalelerin bibliyometrik analizini yaparak bu alanda yapılan çalışmaların seyrinin yıllar içerisinde nasıl değiştiğinin belirlenmesidir. Buna göre, çalışmanın amacı doğrultusunda tersine lojistik alanındaki çalışmaların sosyal ve entelektüel yapıs1 nedir sorusunun cevabı aranmıştır. Bu doğrultuda 2000-2019 yılları arasında tersine lojistik alanında yapılan çalışmalar taranmış ve konuyla ilgili detaylı bilgiler sunmak üzere $\mathrm{R}$ programı ile görselleştirme yapılmıştır. Dünyada tersine lojistik konusu ile ilgili bibliyometrik çalışmaların kısıtlı olması, bu konuda Türkiye'de yapılan çalışmalara rastlanılmaması ve sayıca az olduğunun düşünülmesi yapılan bu çalışmanın özgünlüğünü göstermektedir. Ayrıca bu çalışmanın, ilgili konuda yapılan çalışmaların yönünü ve eğilimlerini göstermesi ve bu alanda araştırma yapmayı düşünen araştırmacılara yol gösterici olması bakımından fayda sağlaması beklenmektedir.

\section{Literatür}

\subsection{Tersine Lojistik}

Tersine lojistik, ürünlerin yeniden kullanımı, onarımı, yeniden üretimi, geri dönüşümü veya elden çıkarılması amacıyla toplanabilmesi için gereken faaliyetleri ifade etmektedir. Literatürde tersine lojistiğin çeşitli tanımları bulunmaktadır. Murphy ve Poist (1988) tersine lojistiği tanımlayan ilk araştırmacılardır ve tersine lojistiği ürünlerin geriye doğru akışı olarak ifade etmişlerdir. Stock (1998), Rogers ve Tibben-Lembke (1999) ve Dowlatshahi (2000) tersine lojistik tanımını farklı bakış açılarıyla geliştirmiş ve yeni tanımlar oluşturmuşlardır. Güleş vd. (2012) tersine lojistiği hammadde, mamul ve malzemelerin yeniden kullanımı, geri dönüşümü veya çevreye zarar vermeyecek biçimde bertaraf edilmesi için tüketim merkezinden üretim kaynağına geri yönlü akışı olarak tanımlamışlardır. En genel anlamda bu süreç, kiralık ekipman ve makineler de dahil olmak üzere kullanılmış ya da iade edilen ürünlerin toplanmasi, denetlenmesi, geri dönüştürülmesi, yenilenmesi ve yeniden üretilmesini içermektedir (Alumur vd., 2012: 67).

Lojistik yalnızca bir ürünün ileri yönlü akışı olmamaktadır. İleri lojistikte; belirli bir rotada bir noktadan çok sayıda noktaya dağıtım söz konusudur. Tersine lojistikte ileri yönlü lojistikten farklı olarak mamul ve malzemelerin tüketiciden üretim merkezine doğru akışı söz konusudur (Erturgut, 2016: 232-233). Müş̧terilerin gerektiğinde ürünü iade edebileceklerini bilmeleri işletmeye olan güvenlerini arttıracak ve bu durum işletmelere rekabet gücü kazandıracaktır. Ayrıca tersine lojistik, işletmelerin esnekliğini de artırmaktadır. Birçok işletme, satamadıkları ürün stoklarına sahiptir. Eğer bu stoklar kolayca bileşenlerine ve materyallerine ayrıştırılabilirse işletmenin pazarda başarılı olma şansı da artacaktır (Karaçay, 2005: 322). 
Literatürde sayıca az olsa da Wang vd. (2017), De Lima Simão vd. (2018), Kazemi vd. (2019), Ren vd. (2019), Gallegos vd. (2019), Chaves vd. (2019) tersine lojistiğe ilişkin bibliyometrik analiz çalışmaları bulunmaktadır. $\mathrm{Bu}$ çalışmaların bir kısmına bibliyometrik çalışmalar başlığında değinilmiştir. Tersine lojistik alanındaki bibliyometrik çalışmaların sayıca az olması nedeniyle bibliyometrik çalışmalar başlığında tedarik zinciri yönetimi, yeşil lojistik, afet ve insani yardım lojistiği, kent lojistiği gibi lojistik alanındaki diğer konulara ilişkin bibliyometrik analizlere de detaylı bir şekilde yer verilmiştir.

\subsection{Bibliyometrik Çalışmalar}

Broadus (1987), bibliyometriyi herhangi bir bilimsel dergide yayınlanmış çalışmaların nicel olarak incelenmesi şeklinde tanımlamaktadır. OECD (2002)'ye göre ise bibliyometri, bilimsel yayınların profilleri hakkında elde edilen bilgileri kapsayan bir terimdir. Bibliyometrik analizler çoğunlukla bir makalenin yayınlandığı dergi, yazarı/yazarları, başlığı, konusu, anahtar kelimeleri ve bağlantıları ile ilgili bilgiler sunmaktadır (Dolati Neghabadi vd., 2019: 4). Bu bölümde bibliyometrik analiz kullanılan çalışmaların özetine yer verilmiştir.

Charvet vd. (2008), tedarik zinciri yönetimi alanındaki çalışmaları bibliyometrik analiz yöntemi ile incelemişlerdir. Yazarlar, tedarik zinciri yönetimi teriminin akademik literatürde kullanımını, yapılan çalışmaların zaman içerisinde nasıl gelişim gösterdiğini ve bu alanda yapılan yayınları inceleyerek tedarik zinciri yönetimine olan ilgi ve çalışma eğiliminin değişimini ortaya koymayı amaçlamışlardır. Çalışmada; anahtar kelime olarak tedarik zinciri yönetimi kullanılmış ve ilk etapta 1985 Ocak - 2005 Aralık arasında bu anahtar kelimeyi içeren tüm makaleler veri olarak alınmıştır. Yapılan araştırma sonucunda 1467 makale elde edilmiştir. Daha sonra veriler bu alanda en fazla makale yayınlayan dergiler ile sınırlandırılmış ve makale sayısı 915'e düşürülmüştür. Analizler sonrasında; tedarik zinciri yönetimi alanında en fazla makale yayınlayan derginin 85 makale ile International Journal of Physical Distribution and Logistics Management olduğu, bu alanda en fazla atıf alan makalenin 159 atıfla Management Science dergisinde yayınlan Lee vd.'nin (1997) makalesi olduğu, tedarik zinciri yönetimi alanında yapılan çalışmaların belirlenen yıl aralı̆g 1 içerisinde özellikle 2003, 2004 ve 2005 yıllarında yoğunlaşmış olduğu ve makalelerin yayınlandığı dergiler arasında endüstri mühendisliği, bilgi sistemleri, yönetim ve strateji ve pazarlama alanında makale yayınlayan dergilerin bulunduğu elde edilen sonuçlardan bazılarıdır.

De Campos vd. (2017), ilaç endüstrisinde ömrünü tamamlamış ve kullanım sonu ürünlerde tersine lojistik uygulamaları ile ilgili literatür incelemesi yaparak tersine lojistik alanı ile ilgili araştırma alanlarını ve bu alandaki boşlukları belirlemeyi ve ilaç endüstrisinde tersine lojistik konulu çalışmalarla ilgili gelişmeleri ortaya koymayı amaçlamışlardır. Çalışmada yıl aralığı 1995-2016 olarak kısıtlanmış, makale aramaları ise Web of Science, 
Tersine Lojistik Alanındaki Yayınların Bibliyometrik Analiz Yöntemiyle Değerlendirilmesi

Science Direct, Scopus ve Emerald veri tabanlarından gerçekleştirilmiştir. Bu veri tabanlarından toplamda 753 yayın alınmış, analizler ve görselleştirme ise VOSviewer programı kullanılarak yapılmıştır. Analizlere sonucunda; bu alanda en fazla çalışma yapan iki ülkenin 244 yayınla Birleşik Krallık ve 183 yayınla ABD olduğu, en fazla atıf alan derginin Supply Chain Management dergisi olduğu, bu alanda en fazla yayını olan üniversitenin Cranfield Universitesi olduğu, en sık kullanılan anahtar kelimenin tedarik zinciri yönetimi olduğu belirlenmiştir.

Wang vd. (2017), 1992-2015 yılları arasında tersine lojistik alanında yapılan çalışmaları bibliyometrik analiz yöntemiyle incelemişlerdir. Çalışmanın amacı; tersine lojistik alanında yapılan çalışmaların alana katkılarını belirlemek ve bu çalışmaların gelecekteki araştırmalara nasıl yön verebileceğini ortaya koymaktır. Yazarlar verileri elde etmek için Web of Science veri tabanını kullanmışlar, bu veri tabanından tersine lojistik alanında yayınlanmış 912 makaleyi almışlar ve analizler ile görselleştirmeyi CiteSpace programıla yapmışlardır. Yapılan analizler incelendiğinde; tersine lojistik alanındaki çalışmaların 2009 yılı itibariyle hızla arttığı, en fazla çalışmanın 123 çalışma ile 2013 yılında yapıldığı, en çok sayıda ve en fazla atıf alan çalışmaların Guide ve Van Wassenhove tarafindan yapıldığ yeşil lojistik, sürdürülebilirlik, ürün yaşam döngüsü yönetimi, ürün iadeleri, yeniden üretim, tersine lojistik ağı, tersine lojistik ve tedarik zinciri olduğu görülmektedir.

Braz vd. (2018), ileri yönlü tedarik zincirlerindeki kamçı etkisinin nedenlerini araştırmış ve bunların kapalı döngü tedarik zincirleri ile karşılaştırılmasını amaçlamışlar, buna yönelik olarak bu alanda yayınlanan makalelerin taramasını yapmak amacıyla bibliyometrik analiz yöntemini kullanmışlardır. Çalışmada 2016 yılı Aralık ayına kadar dergilerde ve konferanslarda İngilizce dilinde yayınlanmış makaleler incelenmiştir. Belirlenen 291 çalışma içerisinde, çalışmaların özet başlık ve araştırma konusu ile uyumluluğuna göre incelemeler yapılarak bu sayı 32'ye düşürülmüş ve analiz bu sayı üzerinden gerçekleştirilmiştir. Yapılan analiz sonrasında; makaleler kategorilere göre kodlanmış ve analiz edilmiş, bu alandaki çalışmaların yapıldığı dergiler ve çalışmaların yıllara göre dağılımları belirlenmiştir. Buna göre; belirlenen 32 çalışmada konferanslarda sunulan ve bildiri kitabında makale olarak yayınlanan 11 makaleden 9'unun 2011'e kadar yayınlanmış olduğu, dergilerde yayınlaşmış olan 21 makaleden 16'sının da 2011 sonrasında yayınlandığı, en fazla çalışmanın yapıldığı yılın 2016 yılı olduğu, çalışmaların birçoğunun mühendislik, modelleme ve simülasyon araştırmaları içerdiği sonucuna ulaşılmıştır.

De Lima Simão vd. (2018), tersine lojistik alanında yapılan çalışmaları bibliyometrik analiz yöntemiyle incelemişlerdir. Yaptıkları araştırmada tersine lojistikte ortaya çıkan bilimsel ve teknolojik alanları bibliyometrik ağları kullanarak ortaya çıkarmayı amaçlamışlardır. Çalışmada tersine lojistik 
alanındaki makaleler Web of Science veri tabanından alınmıştır ve analizler 841 çalışma üzerinden gerçekleştirilmiştir. Analizler; Sci2Tool ve CiteSpace programları kullanılarak yapılmıştır. Yazarlar, yapılan analizler sonucunda; tersine lojistik alanında çalışan yazarlar ile ilgili temel bilgileri, yazarların ülke atıfları ve ağ yoğunluğu gibi hususları ortaya koymuşlardır.

Teixeira vd. (2018), yeşil lojistik ve yeşil tedarik zinciri yönetimi alanında 2013-2017 yılları arasında yapılan çalışmaları bibliyometrik analiz yöntemiyle incelemişlerdir. Yazarlar, bu alanda yapılan çalışmaları $A C M$, EBSCO, Emerald, Academic OneFile (GALE), Scielo, Sciense Direct, Springer, Web of Science ve Wiley veri tabanlarından almışlardır. Çalışma türü olarak bilimsel makaleler ele alınmıştır ve yazarlar arama yapmak için Portekizce ve İngilizce olmak üzere iki dil kullanmışlardır. Anahtar kelimeler olarak; tedarik zinciri yönetimi, yeşil tedarik zinciri yönetimi, yeşil lojistik, sürdürülebilir satın alma kelimeleri kullanılmıştır. Yapılan analizlerin ardından, bu alanda en fazla yayın yapan ülkenin ABD olduğu, bu konuda en fazla yayın yapan derginin ise Journal of Cleaner Production olduğu sonucuna ulaşmışlardır.

Tisott vd. (2018), 1994-2016 yılları arasında afet ve insani yardım lojistiği alanındaki çalışmaları bibliyometrik analiz yöntemiyle incelemişlerdir. Bu çalışmada; afet ve insani yardım lojistiği alanında en fazla yayın yapan dergileri, bu konuda en fazla çalışan yazarları ve bu alanda kullanılan anahtar kelimeleri belirlemek amaçlanmıştır. Çalışmada veriler Scopus veri tabanından elde edilmiştir. Arama için kullanılan anahtar kelimeler; insani yardım, yardım, kriz, acil durum, afet ve lojistik, tedarik zinciri, operasyonlar, motivasyon, gönüllü ve gönüllülük kelimeleri olmuştur. Buna göre; belirlenen yıllar arasında 144 makaleye ulaşılmıştır. Yapılan analizde; bu alanda en fazla atıf alan derginin International Journal of Production Economics olduğu, en fazla atıfin 2006 yılında gerçekleştiği, afet ve insani yardım lojistiği alanında en fazla çalışma yapan ülkelerin sırasıyla İrlanda, İtalya, İsveç, Japonya, İran, Peru, Brezilya, Malezya, Güney Kore ve Tayvan olduğu, yapılan yayınların büyük çoğunluğunun 2010-2015 yıllarında yoğunlaştığı, konu ile ilgili en sı kullanılan anahtar kelimelerin; insani lojistik, afetler ve tedarik zinciri yönetimi kelimeleri olduğu sonucuna ulaşılmıştır.

Dolati Neghabadi vd. (2019), kent lojistiği alanında yapılan çalışmaları bibliyometrik analiz yöntemiyle incelemişlerdir. $\mathrm{Bu}$ çalışmada veriler; konferanslarda sunulan bildiriler, bilimsel dergilerde yayınlanan makaleler, kitaplar ve kitap bölümlerinden elde edilmiştir. Yazarlar; 2010-2016 yılları arasında bu alanda yayınlanan 370'den fazla çalışmayı inceleyerek kent lojistiği alanında en sık kullanılan anahtar kelimeler ve bu alandaki araştırmalar için yeni bakış açılarını tanımlayan kategoriler hakkında bilgi vermişlerdir. Yapılan analizler sonrasında; kent lojistiği alanında özellikle konferansta bildiri olarak sunulan ve yayınlanan çalışmaların 2012 yılından itibaren arttı̆̆ yarısından fazlasının ampirik çalışmalar olduğu, bu alanda en fazla çalışan 
Tersine Lojistik Alanındaki Yayınların Bibliyometrik Analiz Yöntemiyle Değerlendirilmesi

bölgenin Avrupa; en fazla çalışma yapılan iki ülkenin sırasıyla Fransa ve İtalya olduğu ulaşılan sonuçlar arasındadır.

Kazemi vd. (2019), 2000-2017 y1lları arasinda International Journal of Production Research (IJPR)'de yayınlanan tersine lojistik ve kapalı döngü tedarik zinciri yönetimi ile ilgili çalışmaları incelemek için bibliyometrik analiz yöntemini kullanmışlardır. Analizler VOSviewer programı ile yapılmıştır. Belirlenen yıl aralığında bu konularda yayınlanmış olan 94 çalışmanın içeriği değerlendirilmiştir. Buna bağlı olarak yazarlar tersine lojistik ve kapalı döngü tedarik zinciri yönetimi konularında gelecek çalışmalar için yol gösterici niteliğe sahip olacak literatür boşluklarını da ortaya koymayı amaçlamışlardır. $I J P R$ 'deki yayınlar alınmadan önce tersine lojistik ve kapalı döngü tedarik zinciri yönetimi konularındaki yayınların nicel analizi yapılmış ve bunun için Web of Science ve Scopus veri tabanlarından faydalanılmış daha sonra yayınlar $I J P R$ 'deki yayınlar ile sınırlandırılmıştır. İlk aramalar sonrasında 2566 makale bulunmuştur. Yayın sayısı bakımından 2000'lerden sonrasının daha önemli bir rol oynadığı anlaşılmıştır. 2016 yılının bu alanlarda yayınlanan çalışmaların en yüksek olduğu yıl olduğu, makalelerin \%80'inin son on yılda yayınlandığ International Journal of Production Economics ve International Journal of Production Research dergisinin bu alanlara en fazla katk1 yapan dergi olduğu belirlenmiştir. Buna göre, yazarlar IJPR'de yayınlanan makalelere odaklanarak çalışmayı sınırlandırılmıştır. Analizlere göre; IJPR'de bu alanlarda yapılan çalışmaların 2010 yılından sonra yoğunlaştı̆̆ yılın 2012, bu konularda en fazla çalışan ülkenin ABD, en çok atıf yapılan yayının Krikke vd.'nin (2003) çalışması olduğu, en sık kullanılan anahtar kelimelerin de tersine lojistik, yeniden üretim, kapalı döngü tedarik zinciri olduğu ulaşılan sonuçlar arasında yer almaktadır.

Savrun ve Mutlu (2019), kent lojistiği alanında yapılan çalışmaları bibliyometrik analiz yöntemiyle incelemişlerdir. Yazarlar veri elde etme aşamasında Scopus ve Web of Science veri tabanlarından faydalanmış, kent lojistiği anahtar kelimesi ile arama yaparak bu veri tabanları üzerinden kent lojistiği alanında elde ettikleri kitap, bildiri ve makaleler ile bu alandaki yazar profili, yazar sayısı, makale sayısı, yayın yılı, makale konusu ile ilgili bilgileri derleyerek kent lojistiği alanında yapılan çalışmaların çerçevesi ile ilgili bilgileri aktarmışlardır. Çalışmada elde edilen verilerin düzenlenmesinde ve görselleştirilmesinde Microsoft Excel 2016 ve VOSviewer programları kullanılmışır. Yapılan analizler sonucunda kent lojistiği alanında en fazla çalışmanın yapıldığ 1 yılın 2016 olduğu, yapılan çalışmaların büyük çoğunluğunun konferans bildirilerinden oluştuğu, bu alanda en fazla çalışma yapan ülkenin Çin olduğu, bölgesel olarak bakıldığında ise Avrupa Birliği (AB) ülkelerinin bu alanda en fazla çalışma yapan ülkeler olduğu, kent lojistiği alanında en fazla alıntılanan çalışmanın Crainic vd.'nin (2009) çalışması olduğu, kent lojistiği alanında farklı alanların da çalışmalarının olduğu sonucuna ulaşı1mıştır. 


\section{3. Çalışmanın Yöntemi}

Bu çalışmada tersine lojistik alanında yayınlanan makalelerin uluslararası atıf indekslerinde taranan çalışmalara ait bibliyometrik özelliklerinin belirlenmesi amaçlanmaktadır. Web of Science (WOS) veri tabanı üzerinden konu başlığı (topic) "tersine lojistik (reverse logistics)" olarak arama yapılmıştır. Öncelikle; tersine lojistik alanında yapılmış yayınlara ulaşmak için Web of Science indeksleri (SSCI, A\&HCI, SCI-Expanded, CPCI-S, CPCI-SSH, $E S C I)$ filtrelemesi yapılmıştır. Daha sonra, araştırmaya konu olan yayınlara ait kriterler; 2000-2019 yılları arasında, İngilizce dilinde ve makale türünde yayınlanmış yayınlar olarak belirlenmiştir. 18.01.2020 tarihinde analize ait veriler için arama yapılmıştır (WOS, 2020). Çalışma, yayınlanmış 1850 makaleyi kapsamaktadır ve bu verilere bibliyometrik analiz uygulanmıştır.

Atıf analizi kapsamında öncelikle tersine lojistik alanında incelenen 1850 makalenin yıllara göre atıf sayıları ve yayınların dağılımlarına ait genel özellikler incelenmiş̧ir. Makalelerde kullanılan anahtar kelimeler faktör analizi ile yorumlanmış, anahtar kelimelere ait trendler yıllar itibari ile incelenmiştir. Tersine lojistik çalışmalarının kaç kaynağa atıf yaptığı ve WOS veri tabanında belirlenen çalışmalara yapılan atıf sayılarına ait dağılımları değerlendirilmiştir. Ayrıca kategorik temelde kümeleme analizleri ile yayın alanları, yazarlar, yayın kaynakları, ülkeler, enstitüler $\mathrm{R}$ programı uygulaması ile görselleştirilerek analiz sonuçları ile birlikte ortaya konulmuştur.

\section{4. Çalışmanın Bulguları}

Tersine lojistik ile ilgili hazırlanan bibliyometrik çalışmada, 2000-2019 yıllarına ait toplam 1850 makale WOS veri tabanı üzerinden elde edilmiştir. Şekil 1 ve Tablo 1'de özet bilgilere yer verilmiştir.

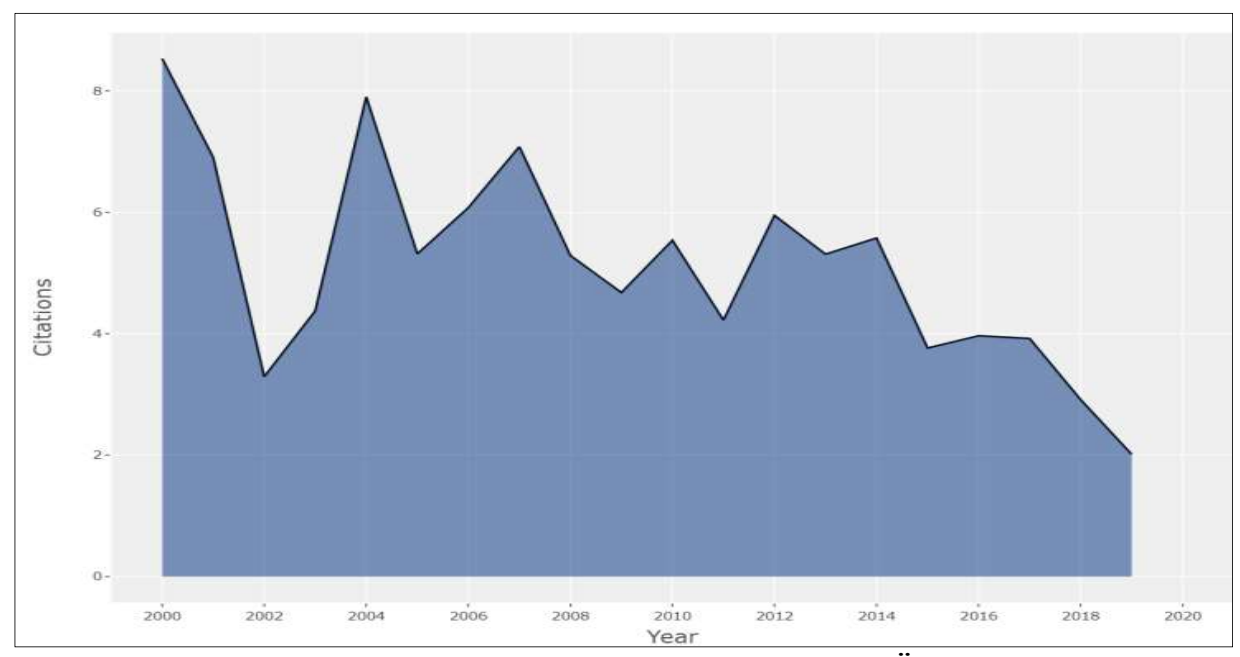

Şekil 1: Yıllara Göre Atıf Satıları ve Genel Özellikler 
Tersine Lojistik

Alanindaki

Değerlendirilmesi

Tablo 1: Analiz Edilen Makalelere Ait Genel Özellikler

\begin{tabular}{|l|l|}
\hline İncelenen Dönem & $2000-2019$ \\
\hline Makale & 1850 \\
\hline Dergi & 440 \\
\hline Anahtar Kelime & 2018 \\
\hline Yayın Başına Ortalama Atıf & 28,04 \\
\hline Tek Yazarlı Yayınların Sayısı & 134 \\
\hline Cok Yazarı Yayınların Sayısı & 3531 \\
\hline Tek Yazarlı Yayın Sayısı & 151 \\
\hline Yazar Başına Düşen Yayın & 1,98 \\
\hline Doküman Başına Düşen Yazar & 3 \\
\hline İşbirliği Endeksi & 2,08 \\
\hline
\end{tabular}

Şekil 1 ve Tablo 1'e göre; 1850 makale 440 farklı dergide yayınlanmıştır. Yayın başına ortalama atıf sayısı 28,04 'dür. Yazar başına düşen yayın sayısı 1,98 , makale başına düşen yazar sayısı ise 3 'tür. İncelenen dönem için ortalama yıllık atıf sayılarının en yüksek olduğu yıl 2000 yılıdır. Yıllara göre atıf sayıları incelendiğinde 2018 yılı sonrasında tersine lojistik konusuna olan ilginin önceki yıllara kıyasla azalmakta olduğu ve atıf sayılarının düşme eğiliminde olduğu görülmektedir.

Anahtar kelimeler yayınların içeriğinin özetlenmesi ve daha görünür olmasını sağlamasının yanında, sık kullanılan anahtar kelime grupları yayınlanan alan ile ilgili sıkça değinilen konu ve kavramlara karşl1ık gelmektedir. Tersine lojistik alanında incelenen 1850 makalenin anahtar kelimelerine göre Şekil 2'de "yönetim (management)" kelimesi tersine lojistik kelimesinden sonra en sik kullanılan kelime iken, bu kelimeleri takiben sirasiyla "model, dizayn (design), ürün geri kazanımı (product recovery), performans (performance) ve optimizasyon (optimization)" kelimelerinin yüksek sıklıkta kullanıldığı gözlenmektedir.

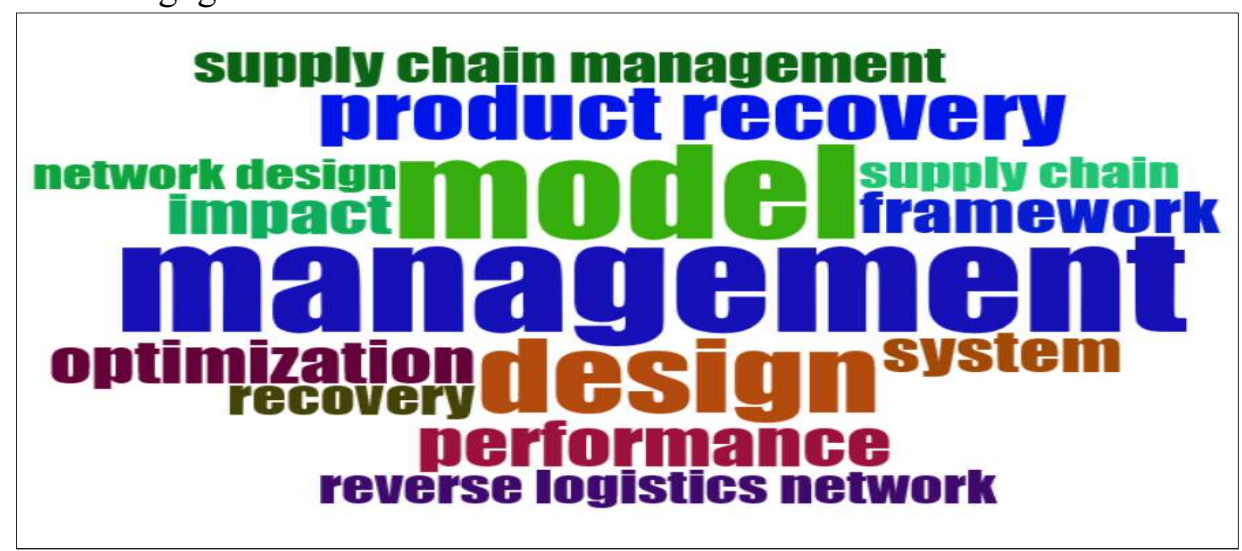

Şekil 2: Kelime Bulutu 
Şekil 3'de anahtar kelimelere (keywords plus) Multiple Correspondence Analysis (MCA) yöntemi uygulanarak faktör analizi yapılmıştır. Faktör analizi verilerin boyutsallığını azaltarak verilerin daha düşük boyutlarda temsil edilmesini sağlamaktadır (Bibliometrix, 2020). Çalışmada makalelerde kullanılan anahtar kelimelerin ağırlıklı olarak birlikte kullanılıp kullanılmamasına göre birbirlerine yakınlık ve uzaklıkları faktör analizi ile kümelenerek kavramsal yapı haritası oluşturulmuştur. Tersine lojistik alanında yapılan çalışmaların kavramsal yapılarının iki grupta kümelendiği görülmektedir. 1. grup (mavi renkli küme) tedarik zinciri yönetimi, sürdürülebilirlik, performans konularında kümelenirken, 2. grup (kırmızı renkli küme) tersine lojistik, uygulamaları ve optimizasyon konularında kümelenmiştir.

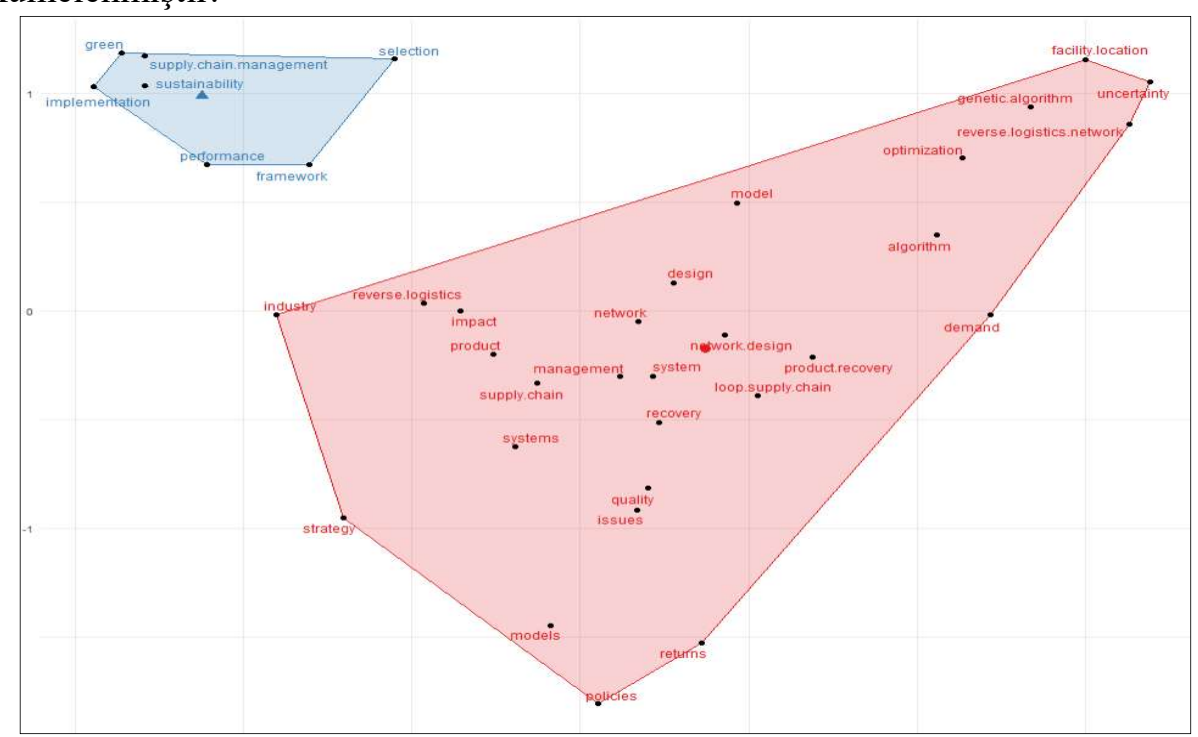

Şekil 3: Kavramsal Yapı Haritası

Şekil 4'de tersine lojistik alanında yapılan çalışmalarda kullanılan anahtar kelimelerin yıllar itibari ile kullanım sıklı̆̆ incelenmiştir. Buna göre; "tersine lojistik" kelimesi alanda özellikle 2007 yıllından itibaren daha s1k kullanılmaya başlanmış, 2018-2019 yıllarında ise oldukça popüler hale gelmiştir. Yönetim, model ve dizayn kelimeleri son yıllarda bu alanda en fazla kullanılan kelimeler arasındadır. 2012 yılından sonra performans ve optimizasyon kelimelerinin kullanımında da belirgin bir artış görülmektedir. 
Tersine Lojistik

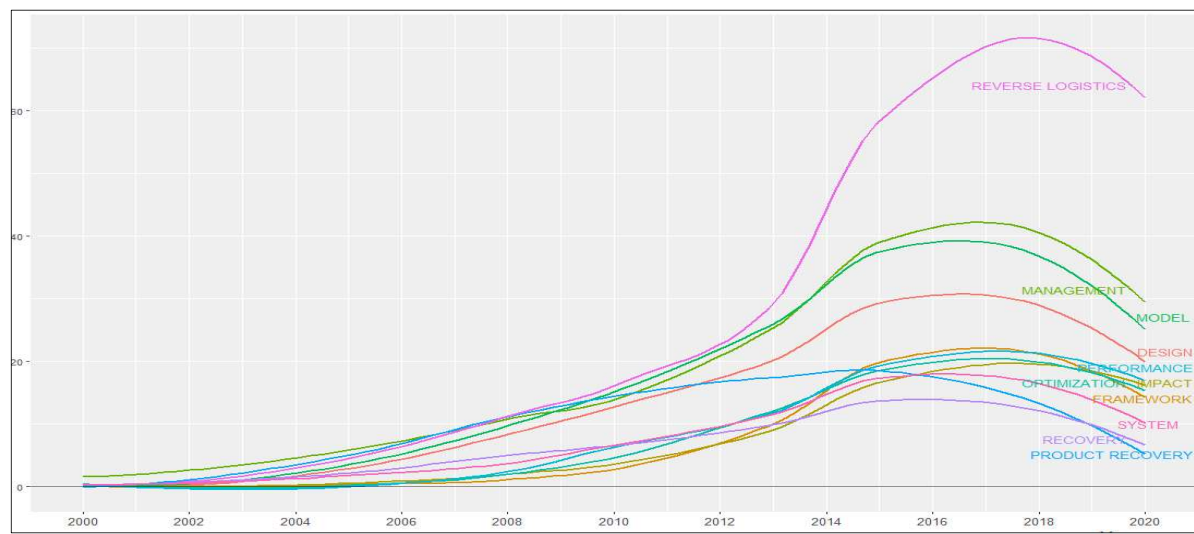

Şekil 4: Anahtar Kelime Trendleri

Tablo 2'de tersine lojistik ile ilgili 1850 makalenin yayınlandığı dergiler siralanmıştır. Journal of Cleaner Production 2000-2019 y1lları arasında 164 makale ile bu alanda en fazla makale yayınlayan dergidir. International Journal of Production Economics ise tersine lojistik alanında en fazla atıf alan dergidir. International Journal of Production Economics dergisi yayın sayıs1 olarak ikinci sırada yer alsa da diğer tüm değerler incelendiğinde bu derginin tersine lojistik alanında en etkili dergilerden biri olduğu görülmektedir.

Tablo 2: Kaynak Etkisi

\begin{tabular}{|l|l|l|l|l|l|}
\hline Kaynak & $\mathbf{h}$ _index & $\mathbf{g}$ index & $\mathbf{m}$ index & TC* & NP* \\
\hline $\begin{array}{l}\text { JOURNAL OF CLEANER } \\
\text { PRODUCTION }\end{array}$ & 37 & 55 & 2,17 & 3819 & 164 \\
\hline $\begin{array}{l}\text { INTERNATIONAL JOURNAL OF } \\
\text { PRODUCTION ECONOMICS }\end{array}$ & 46 & 77 & 2,30 & 6598 & 130 \\
\hline $\begin{array}{l}\text { INTERNATIONAL JOURNAL OF } \\
\text { PRODUCTION RESEARCH }\end{array}$ & 34 & 49 & - & 2894 & 108 \\
\hline $\begin{array}{l}\text { COMPUTERS \& INDUSTRIAL } \\
\text { ENGINEERING }\end{array}$ & 24 & 44 & 1,60 & 1963 & 57 \\
\hline $\begin{array}{l}\text { EUROPEAN JOURNAL OF } \\
\text { OPERATIONAL RESEARCH }\end{array}$ & 35 & 55 & 1,84 & 3993 & 55 \\
\hline $\begin{array}{l}\text { RESOURCES CONSERVATION } \\
\text { AND RECYCLING }\end{array}$ & 27 & 46 & 1,35 & 2184 & 54 \\
\hline SUSTAINABILITY & 7 & 12 & 1,00 & 212 & 49 \\
\hline $\begin{array}{l}\text { INTERNATIONAL JOURNAL OF } \\
\text { ADVANCED MANUFACTURING } \\
\text { TECHNOLOGY }\end{array}$ & 18 & 33 & 1,38 & 1123 & 40 \\
\hline $\begin{array}{l}\text { PRODUCTION PLANNING \& } \\
\text { CONTROL }\end{array}$ & 14 & 23 & - & 555 & 30 \\
\hline $\begin{array}{l}\text { INTERNATIONAL JOURNAL OF } \\
\text { PHYSICAL DISTRIBUTION \& } \\
\text { LOGISTICS MANAGEMENT }\end{array}$ & 15 & 26 & 1,15 & 727 & 28 \\
\hline $\begin{array}{l}\text { OMEGA-INTERNATIONAL } \\
\text { JOURNAL OF MANAGEMENT } \\
\text { SCIENCE }\end{array}$ & 20 & 28 & 0,95 & 2125 & 28 \\
\hline
\end{tabular}


Gamze ALKAN - Burcu YILMAZ - Suzan OĞUZ

\begin{tabular}{|l|l|l|l|l|l|}
\hline $\begin{array}{l}\text { COMPUTERS \& OPERATIONS } \\
\text { RESEARCH }\end{array}$ & 20 & 25 & 1,33 & 2059 & 25 \\
\hline $\begin{array}{l}\text { INTERNATIONAL JOURNAL OF } \\
\text { LOGISTICS MANAGEMENT }\end{array}$ & 10 & 18 & 0,76 & 351 & 24 \\
\hline $\begin{array}{l}\text { APPLIED MATHEMATICAL } \\
\text { MODELLING }\end{array}$ & 14 & 23 & 1,27 & 1411 & 23 \\
\hline $\begin{array}{l}\text { TRANSPORTATION RESEARCH } \\
\text { PART E-LOGISTICS AND } \\
\text { TRANSPORTATION REVIEW }\end{array}$ & 17 & 23 & 0,89 & 1666 & 23 \\
\hline $\begin{array}{l}\text { EXPERT SYSTEMS WITH } \\
\text { APPLICATIONS }\end{array}$ & 18 & 21 & 1,50 & 1363 & 21 \\
\hline $\begin{array}{l}\text { SUPPLY CHAIN MANAGEMENT- } \\
\text { AN INTERNATIONAL JOURNAL }\end{array}$ & 13 & 21 & 0,72 & 719 & 21 \\
\hline $\begin{array}{l}\text { JOURNAL OF } \\
\text { MANUFACTURING SYSTEMS }\end{array}$ & 14 & 20 & 1,17 & 701 & 20 \\
\hline $\begin{array}{l}\text { BENCHMARKING-AN } \\
\text { INTERNATIONAL JOURNAL }\end{array}$ & 7 & 9 & - & 109 & 19 \\
\hline
\end{tabular}

*TC: Toplam Atıf Sayıs *NP: Toplam Makale Sayısı

*h_indeks, g_indeks ve m_indeks: Yayınların üretkenliğini ve atıf etkisini ölçen ölçütler

Tablo 3'de görüldüğü gibi Kannan Govindan 38 makale ile tersine lojistik alanında en fazla çalışan ve 2416 atıf ile en fazla atıf alan yazardır. Şekil 5'deki referans, yazar ve anahtar kelimelere ait üç alan grafiği Govindan'ın çalışmalarında en fazla tersine lojistik, sürdürülebilirlik ve tedarik zinciri yönetimi anahtar kelimelerini kullandığını göstermektedir. Alanda en fazla atıf alan (1496 atıf) bir diğer yazar Joseph Sarkis'in da en fazla kullandığı anahtar kelimeler tersine lojistik, sürdürülebilirlik ve tedarik zinciri yönetimidir.

Tablo 3: Yazar Etkisi

\begin{tabular}{|l|l|l|l|l|l|}
\hline Yazar & h_index & g_index & m_index & TC$^{*}$ & NP* $^{*}$ \\
\hline GOVINDAN K & 24 & 38 & 2,67 & 2416 & 38 \\
\hline JABER MY & 13 & 16 & 1,00 & 548 & 16 \\
\hline DIABAT A & 12 & 15 & 1,33 & 594 & 15 \\
\hline KANNAN D & 11 & 14 & 1,22 & 745 & 14 \\
\hline PISHVAEE MS & 10 & 14 & 0,83 & 1337 & 14 \\
\hline GUPTA SM & 8 & 12 & 0,42 & 241 & 12 \\
\hline JHA PC & 7 & 12 & 1,17 & 190 & 12 \\
\hline SARKIS J & 10 & 12 & 0,71 & 1496 & 12 \\
\hline GUNASEKARAN A & 9 & 11 & 1,00 & 611 & 11 \\
\hline LEE DH & 7 & 11 & 0,50 & 401 & 11 \\
\hline
\end{tabular}

*TC: Toplam Atıf Sayıs1, NP: Toplam Makale Sayıs1

*h_indeks, g_indeks ve $\mathrm{m} \_$indeks: Yayınların üretkenliğini ve atıf etkisini ölçen ölçütler 


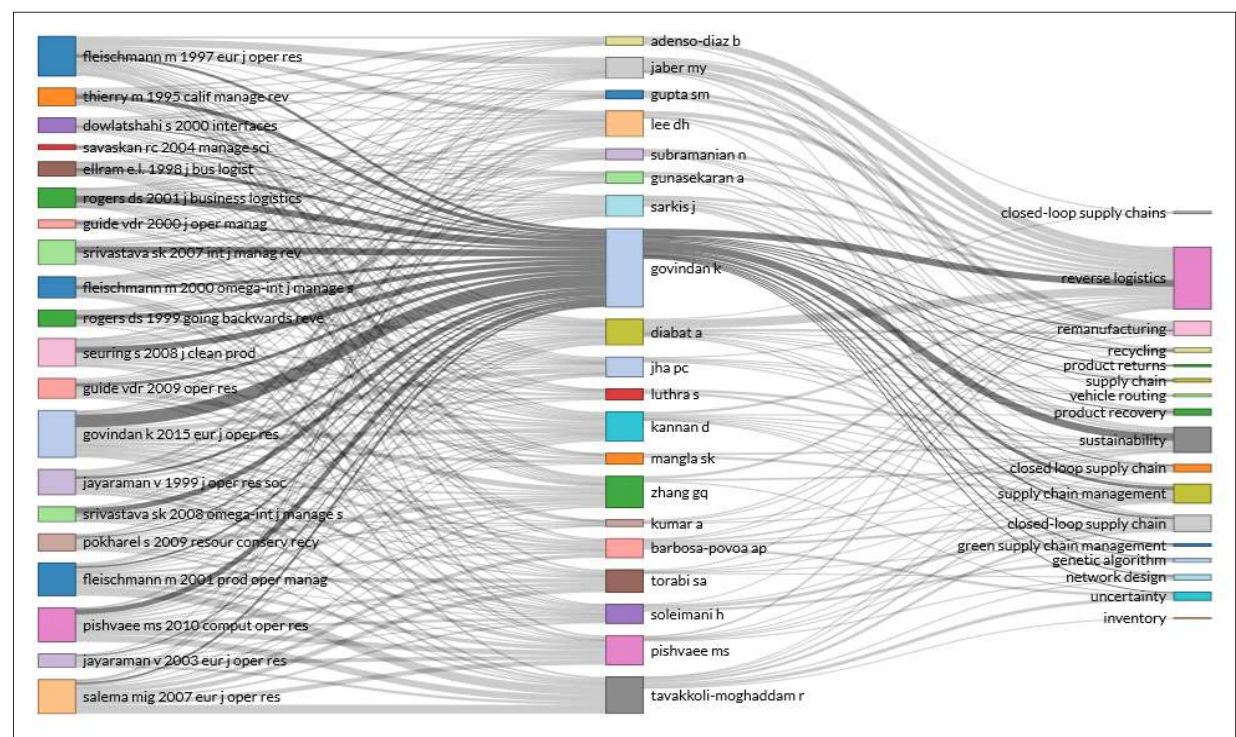

Şekil 5: Referans, Yazar ve Anahtar Kelimelere Ait ÜÇ Alan Grafĭgi

Tersine lojistik ile ilgili en fazla atıf alan çalışmaların yapıldığ 1 ülkelere Tablo 4'de yer verilmiştir. Buna göre; bu alanda en fazla çalışan ilk beş ülke sirasıyla; Amerika (ABD), Kanada, İran, Hollanda ve Çin iken, Türkiye bu alanla ilgili toplam atıf sayısında 10. sirada yer almaktadır.

Tersine lojistik alanına ait iş birliği yapan ülkelerin yoğunlukları Şekil 6'da gösterilmiştir. Tersine lojistik ile ilgili en fazla iş birliği yapan ülkeler; Çin ve ABD'dir (f: 45). Bu iki ülke dışında en fazla iş birliği yapan ülkeler sırasıyla; Hindistan ve Danimarka (f: 24), İngiltere ve Çin (f: 20), Hindistan ve İngiltere (f: 19), Hindistan ve ABD'dir (f: 17). Sonuç olarak Çin, ABD, İngiltere ve Hindistan'ın bu alana en fazla katkı yapan ülkeler olduğu görülmektedir.

Tablo 4: En Fazla Atıfta Bulunulan Ülkeler

\begin{tabular}{|l|l|l|}
\hline Ülke & Toplam Atıf Sayısı & Ortalama Makale Alıntıları \\
\hline USA & 11211 & 57,79 \\
\hline CANADA & 3915 & 48,94 \\
\hline IRAN & 3375 & 22,65 \\
\hline NETHERLANDS & 3234 & 67,38 \\
\hline CHINA & 3215 & 14,42 \\
\hline INDIA & 2945 & 21,50 \\
\hline GERMANY & 2671 & 43,79 \\
\hline DENMARK & 2490 & 52,98 \\
\hline UNITED KINGDOM & 2008 & 21,36 \\
\hline TURKEY & 1970 & 26,27 \\
\hline
\end{tabular}




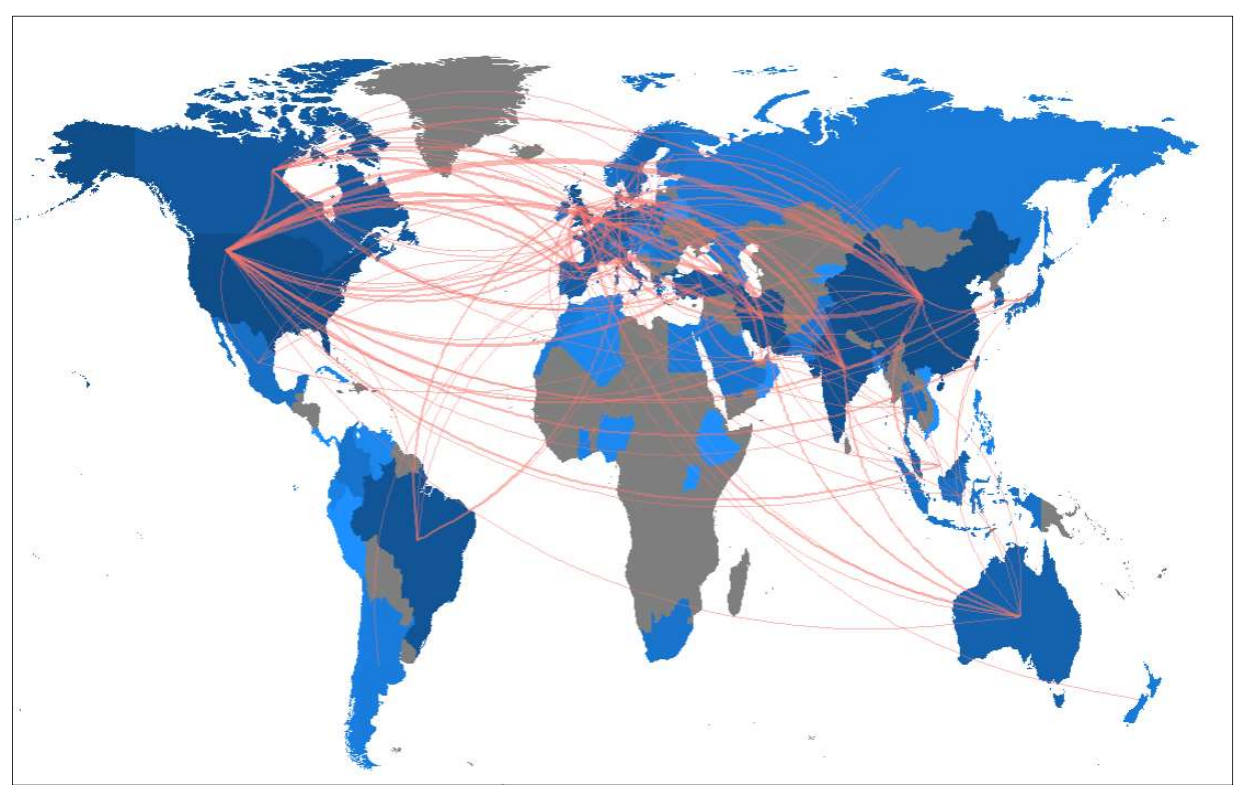

Şekil 6: Ülkeler İşbirliği Haritası

2000-2019 yılları arasında tersine lojistik alanında yayın yapan üniversite siralamasına bakıldığında (Tablo 5); bu alanda en fazla yayın yapan üniversitenin İran'da bulunan Tahran Üniversitesi olduğu görülmektedir. Yayın sayılarına göre sıralamada yer alan ilk 5 üniversitenin 3'ü İran'da bulunan üniversitelerdir.

Tablo 5: Yayın Sayılarına Göre Üniversiteler

\begin{tabular}{|l|l|l|}
\hline ÜNIVERSITELER & ÜLKELER & MAKALE SAYILARI \\
\hline TEHRAN & İRAN & 51 \\
\hline SOUTHERN DENMARK & DANIMARKA & 47 \\
\hline ISLAMIC AZAD & İRAN & 45 \\
\hline INDIAN INST TECHNOLOGY & HINDISTAN & 33 \\
\hline $\begin{array}{l}\text { IRAN UNIVERSITY SCIENCE AND } \\
\text { TECHNOLOGY }\end{array}$ & İRAN & 33 \\
\hline ERASMUS & HOLLANDA & 31 \\
\hline ARISTOTLE UNIV THESSALONIKI & YUNANISTAN & 27 \\
\hline RYERSON UNIV & KANADA & 25 \\
\hline HONG KONG POLYTECH & HONG KONG & 21 \\
\hline NORTHEASTERN & ABD & 21 \\
\hline WINDSOR & KANADA & 21 \\
\hline
\end{tabular}

\section{Sonuç}

Son yıllarda dünyada nüfus artışıla birlikte doğal kaynakların hızla tükenmesi ve pek çok bölgede çevre kirliliğinin artış göstermesi, buna bağlı olarak giderek artan çevresel kaygılar işletmelerin üzerindeki toplumsal ve yasal baskıları arttırmaktadır. Bu nedenle işletmeler tersine lojistik faaliyetlerine daha 
Tersine Lojistik Alanındaki Yayınların Bibliyometrik Analiz Yöntemiyle Değerlendirilmesi

fazla önem vermektedir dolayısıyla bu alanda yapılan faaliyetler de gelişmiş ve gelişmekte olan endüstriler için bir ihtiyaç olarak kabul edilmeye başlanmıştır. Bu bağlamda, akademik alanda da tersine lojistik konusunda yapılan çalışmalar yıllar itibariyle yoğunlaşmış ve bu konuda yapılan çalışmaların sayısında da artış yaşanmıştır.

Bu çalışmada; WOS veri tabanı üzerinden 2000-2019 yıllarına ait "tersine lojistik" başlığı ile taranarak bulunan 1850 makalenin R programı kullanılarak bibliyometrik analizi yapılmış, son 20 yıllık dönemde tersine lojistik alanındaki gelişmeler, eğilimler, bu alanda önde gelen dergi, enstitü ve ülkelere ait analiz sonuçları görselleştirilerek ortaya konulmuştur. İncelenen 1850 makale 440 farklı dergide yayınlanmıştır. Yayın başına ortalama atıf sayısı 28,04'dür. Makale başına düşen yazar sayısı ise üçtür. Son 20 yılda tersine lojistik konusuna ilginin en yüksek olduğu y1l 2000 y1li olduğu ve son y1llar incelendiğinde atıf sayılarında düşüş yaşandığı görülmektedir. Buna göre; son yıllarda tersine lojistik konusuna olan entelektüel ilginin azalmış olduğu ifade edilebilir. Makalelerde yönetim (management) kelimesi tersine lojistik kelimesinden sonra en sık kullanılan anahtar kelimedir ve bu kelimeler dişında en sık kullanılan anahtar kelimelerin sirasıyla "model, dizayn, ürün geri kazanımı, performans ve optimizasyon" kelimeleri olduğu görülmektedir. "Tersine lojistik" kelimesi bu alanda özellikle 2007 y1llından itibaren daha s1k kullanılmaya başlanmış, 2018-2019 yıllarında ise oldukça popüler hale gelmiştir. Yönetim, model, dizayn kelimeleri de son yıllarda alanda en fazla kullanılan kelimelerdir. 2012 yılından sonra performans ve optimizasyon kelimelerinin kullanımında belirgin bir artış izlenmektedir. Çalışmaların kavramsal yapıları iki grupta kümelenmiştir. 1. grup tedarik zinciri yönetimi, sürdürülebilirlik ve performans iken 2. grup tersine lojistik, uygulamaları ve optimizasyon konularıdır. Bu durum entelektüel ilginin iki farklı ekole sahip olduğunu göstermektedir. Kannan Govindan tersine lojisik alanında en fazla çalışan ve en fazla atıf alan yazardır. Govindan'ın alan ile ilgili çalışmalarında en fazla tersine lojistik, sürdürülebilirlik ve tedarik zinciri yönetimi anahtar kelimelerini kullandığı görülmektedir. Bu alanda en fazla atıf alan bir diğer yazar ise "Joseph Sarkis"dir. Sarkis tarafindan en fazla kullanılan anahtar kelimeler; tersine lojistik, sürdürülebilirlik ve tedarik zinciri yönetimidir. Tersine lojistik ile ilgili en fazla çalışmanın yapıldığı ülkeler; sırasıyla ABD, Kanada, İran, Hollanda ve Çin'dir. Türkiye ise bu alanla ilgili toplam atıf sayısında 10. sırada yer almaktadır. Tersine lojistik alanında en fazla işbirliği yapan ülkeler; Çin ve ABD iken bu alana en fazla katkı yapan ülkeler; Çin, ABD, İngiltere ve Hindistan olmuştur. Tersine lojistik alanında en fazla yayın yapan üniversite İran'da bulunan Tahran Üniversitesi'dir. Yayın sayılarına göre sıralamada yer alan ilk beş üniversitenin üçü İran'da bulunan üniversitelerdir. Journal of Cleaner Production 2000-2019 yılları arasinda bu alanda 164 yayin ile en fazla makale yayını yapan dergidir. International Journal of Production Economics dergisi tersine lojistik alanında en fazla atıf alan dergidir. 
International Journal of Production Economics yayın sayıs1 olarak ikinci sirada yer alsa da derginin diğer tüm değerler incelendiğinde tersine lojistik alanında en etkili dergilerden biri olduğu belirlenmiştir.

Çalışmaya ait bazı sınırlılıklar bulunmaktadır. Bu sınırlılıklardan en önemlisi analize dâhil edilen makalelerin $W O S$ veri tabanından alınmasıdır. Gelecek çalışmalarda Scopus, Elsevier gibi farklı veri tabanlarından elde edilen bilimsel kaynaklarla yapılan analizler ile farklı sonuçlara ulaşılması mümkündür. Analiz sonuçlarının elde edildiği 1850 makaleye 18.01.2020 tarihinde ulaşılmıştır. Bu tarihten sonra veri tabanına eklenen yeni makaleler ile yayınların dağılımı, atıf sayıları, yazar, ülke sayıları, anahtar kelimeler ve bu kelimelerin sayısı farklılık gösterebilecektir. Dolayısıyla farklı bulguların elde edilmesi mümkün olabilecektir. Çalışmada seçilen makaleler; 2000-2019 yılları arasında, İngilizce dilinde, makale türünde ve Web of Science indeksi (SSCI, $A \& H C I$, SCI-Expanded, CPCI-S, CPCI-SSH, ESCI) olarak filtrelenerek analiz edilmiştir. Gelecek çalışmalarda araştırmacılar tersine lojistik alanına ait farklı yayın kriterleri (yayın türü ve dil kriteri gibi) seçerek daha ayrıntılı bir çalışma hazırlayabilirler. $\mathrm{Bu}$ çalışmada bibliyometrik analiz $\mathrm{R}$ programı ile gerçekleştirilmiştir. Gelecek çalışmalar için farklı yöntemler (içerik analizi gibi) veya farklı görselleştirme programları (Vosviewer, Citespace vb.) kullanılarak daha farklı analizler ve görselleştirmeler yapılabilir.

\section{Kaynaklar}

Agrawal, S., Singh, R.K. ve Murtaza, Q. (2015), A Literature Review and Perspectives in Reverse Logistics, Resources, Conservation and Recycling, 97, 76-92.

Alumur, S.A., Nickel, S., Saldanha-da-Gama, F. ve Verter, V. (2012), Multiperiod Reverse Logistics Network Design, European Journal of Operational Research, 220(1), 67-78.

Bibliometrix, (2020), Biblioshiny bibliometrix for no coders, 27.04.2020 tarihinde https://bibliometrix.org/biblioshiny/ adresinden alınmıştır.

Braz, A.C., De Mello, A.M., de Vasconcelos Gomes, L.A. ve de Souza Nascimento, P.T. (2018), The Bullwhip Effect in Closed-loop Supply Chains: A Systematic Literature Review, Journal of Cleaner Production, 202, 376-389.

Broadus, R.N. (1987), Toward a definition of "bibliometrics", Scientometrics, 12(5-6), 373-379.

Charvet, F.F., Cooper, M.C. ve Gardner, J.T. (2008), The Intellectual Structure of Supply Chain Management: A Bibliometric Approach, Journal of Business Logistics, 29(1), 47-73.

Chaves, G.D.L.D., Balista, W.C. ve Comper, I.C. (2019), Logística Reversa: o Estado da Arte e Perspectivas Futuras, Eng Sanit Ambient, 24(4), 821831. 
Tersine Lojistik Alanındaki Yayınların Bibliyometrik Analiz Yöntemiyle Değerlendirilmesi

Crainic, T.G., Ricciardi, N. ve Storchi, G. (2009), Models for Evaluating and Planning City Logistics Systems, Transportation Science, 43(4), 432454.

de Campos, E.A.R., de Paula, I.C., Pagani, R.N. ve Guarnieri, P. (2017), Reverse Logistics for the End-of-life and End-of-use Products in the Pharmaceutical Industry: A Systematic Literature Review, Supply Chain Management: An International Journal, 22(4), 375-392.

de Lima Simão, M.P., Barbosa, D.H., Barbosa, J.S.K., Leal, G.C.L., Galdamez, E.V.C. ve Cotrim, S.L. (2018), Emerging Trends and Collaborative Network Patterns on Reverse Logistics, Independent Journal of Management \& Production, 9(2), 321-339.

Dolati Neghabadi, P., Evrard Samuel, K. ve Espinouse, M.L. (2019), Systematic Literature Review on City Logistics: Overview, Classification and Analysis, International Journal of Production Research, 57(3), 865-887.

Dowlatshahi S. (2000), Developing a Theory of Reverse Logistics, Interfaces, $30(3), 143-155$.

Erturgut, R. (2016), Lojistik ve Tedarik Zinciri Yönetimi, Ankara: Nobel Yayınc1lik.

Gallegos, G.M.C., Jiménez, M.A.V. ve Lara, B.N. (2019), Estudio Bibliométrico Comparativo Entre la Logística İnversa y la Logística Verde, Cimexus, 14(2), 153-169.

Govindan, K. ve Bouzon, M. (2018), From a Literature Review to a Multiperspective Framework for Reverse Logistics Barriers and Drivers, Journal of Cleaner Production, 187, 318-337.

Güleş, H.K., Paksoy, T., Bülbül, H. ve Özceylan, E. (2012), Tedarik Zinciri Yönetimi Stratejik Planlama Modelleme ve Optimizasyon, Ankara: Gazi Kitabevi.

Kaçtıoğlu, S. ve Şengül, Ü. (2010), Erzurum Kenti Ambalaj Atıklarının Geri Dönüşümü İçin Tersine Lojistik Ağ ${ }_{1}$ Tasarımı ve Bir Karma Tamsayılı Programlama Modeli, Atatürk Üniversitesi İktisadi ve İdari Bilimler Dergisi, 24(1), 89-112.

Karaçay, A. G. G. (2005), Tersine Lojistik: Kavram ve İşleyiş, Çukurova Üniversitesi Sosyal Bilimler Enstitüsü Dergisi, 14(1), 317-332.

Kazemi, N., Modak, N.M. ve Govindan, K. (2019), A Review of Reverse Logistics and Closed Loop Supply Chain Management Studies Published in IJPR: A Bibliometric and Content Analysis, International Journal of Production Research, 57(15-16), 4937-4960.

Krikke, H., Bloemhof-Ruwaard, J. ve Van Wassenhove, L. (2003), Concurrent Product and Closed-Loop Supply Chain Design with an Application to Refrigerators, International Journal of Production Research, 41(16), 3689-3719. 
Lee, H.L., Padmanabhan, V. ve Whang, S. (1997), Information Distortion in a Supply Chain: The Bullwhip Effect, Management Science, 43(4), 546558.

Murphy, P.R. ve Poist, R.F. (1988), Management of Logistical Retromovements: An Empirical Analysis of Literature Suggestions, Journal of Transportation Research Forum, 29 (1), 177-184.

Nakıboğlu, G. (2007), Tersine Lojistik: Önemi ve Dünyadaki Uygulamaları, Gazi Üniversitesi İktisadi ve İdari Bilimler Fakültesi Dergisi, 9(2), 181-196.

OECD, (2002), Frascati Manual, Sixth Edition, Paris: OECD.

Ren, R., Hu, W., Dong, J., Sun, B., Chen, Y. ve Chen, Z. (2019), A Systematic Literature Review of Green and Sustainable Logistics: Bibliometric Analysis, Research Trend and Knowledge Taxonomy, International Journal of Environmental Research and Public Health, 17(1), 1-25.

Rogers, D.S. ve Tibben-Lembke, R.S. (1999), Going backwards: reverse logistics trends and practices (Vol. 2). Pittsburgh, PA: Reverse Logistics Executive Council.

Sarkis, J., Helms, M.M. ve Hervani, A.A. (2010), Reverse Logistics and Social Sustainability, Corporate Social Responsibility and Environmental Management, 17(6), 337-354.

Savrun, B. ve Mutlu, H.M. (2019), Kent Lojistiği Üzerine Bibliyometrik Analiz, Kent Akademisi, 12(2), 364-386.

Stock, J.R. (1998). Development and implementation of reverse logistics programs. In Annual Conference Proceedings, Council Of Logistics Management (s. 579-586), Oak Brook, Il: CLM.

Teixeira, C.R.B., Assumpção, A.L., Correa, A.L., Savi, A.F. ve Prates, G.A. (2018), The Contribution of Green Logistics and Sustainable Purchasing for Green Supply Chain Management, Independent Journal of Management \& Production, 9(3), 1002-1026.

Temur, G.T., Ayvaz, B. ve Bolat, B. (2015), Tersine Lojistik Yönetimi Dünya'da ve Türkiye'de Durum, 1. Bask1, İstanbul: Nobel Yayınları.

Tisott, P.B., Tondolo, V.A.G., Longaray, A.A., Camargo, M.E. ve Tondolo, R.D.R.P. (2018), A Bibliometric Analysis Regarding Humanitarian Operations and Critical Situations, Revista GEINTEC-Gestão, Inovação e Tecnologias, 8(3), 4508-4521.

Wang, J.J., Chen, H., Rogers, D.S., Ellram, L.M. ve Grawe, S.J. (2017), A Bibliometric Analysis of Reverse Logistics Research (1992-2015) and Opportunities for Future Research. International Journal of Physical Distribution \& Logistics Management, 47(8), 666-687.

WOS (2020), Web of Science, 18 Ocak 2020 tarihinde http://apps.webofknowledge.com adresinden alındı. 